\title{
La incorporación de Tánger, una batalla perdida de la diplomacia primorriverista
}

\author{
SusAna SueIro SEOANE
}

Debido al gran valor estratégico, económico y político de Tánger, este enclave norteafricano interesaba sumamente a todas las potencias mediterráneas y había estado presente en todos los tratados sobre Marruecos que éstas habían concertado a principios del siglo xx. Tras el paréntesis de la Gran Guerra, había surgido nuevamente la cuestión de la urgente necesidad de que las distintas naciones interesadas fijasen un estatuto que regulase la administración de esta ciudad internacional. Por fin, dicho estatuto había quedado acordado en una conferencia anglofranco-española, en la que Italia no había sido admitida debido a la terminante oposición de Francia. Al principio de las negociaciones, las tres potencias participantes habian mantenido posturas divergentes, si bien las actitudes más irreconciliables eran la francesa y la española hasta el punto de que, durante toda la década de los veinte, el contencioso de Tánger iba a ser, junto con Marruecos, la causa fundamental del antagonismo hispano-francés y del generalizado sentimiento francófobo existente en España. Una y otra nación tratarían de granjearse el apoyo de Inglaterra para contrarrestar sus respectivas aspiraciones. En 1923, ante la imposibilidad de que fuese aceptada la tesis española de inclusión de Tánger en su zona de Protectorado marroquí, el Gobierno - tanto el gabinete liberal del marqués de Alhucemas como, después del 13 de septiembre, el Directorio militar de Primo de Rivera - había decidido apoyar como mal menor la tesis inglesa de la internacionalización, siempre que ello significase una representación puramente honorífica y no real del Sultán que, como nadie ignoraba, era el protegido de Francia y estaba bajo su directa influencia. Pero finalmente, en el curso de las negociacio- 
nes, Francia e Inglaterra habían llegado a un acuerdo sobre un régimen internacional con un claro predominio francés, en el que se reconocía plenamente la soberanía del Sultán. A pesar de lo difícil que para España resultaba "digerii" esta preponderancia gala, Primo de Rivera había considerado finalmente inevitable estampar su firma en el convenio tangerino. En efecto, al crearse este frente unido franco-inglés, España había quedado aislada en sus reivindicaciones y, por otra parte, el Gobierno francés había hecho concebir esperanzas al dictador español de que, a cambio de su adhesión al Estatuto, la vecina República se avendría a algún tipo de colaboración en Marruecos, con vistas a reprimir el movimiento rifeño. Por estas razones, y contra el criterio de gran parte del país, Primo de Rivera había firmado un convenio que no sólo no significaba ninguna mejora de la posición de España en Tánger sino que, por el contrario, suponía un paso atrás, puesto que preveía la desaparición del tabor español, encargado del orden público dentro de la ciudad.

Según el estatuto convenido en París, la administración de Tánger - cuya neutralidad se estipulaba- se ejercería a través del Mendub o representante del Sultán, la Asamblea legislativa, y el administrador, estos dos últimos bajo la vigilancia del Comité de Control. El Mendub, al ser nombrado por el Sultán, estaría bajo la influencia francesa y, en la Asamblea, Francia también predominaría. El administrador era asimismo de nacionalidad francesa ${ }^{1}$.

\section{EL FRACASO DEL ESTATUTO DE 1923}

En 1926, todas las potencias implicadas estaban de acuerdo en que, en las circunstancias en las que el Estatuto estaba siendo aplicado, Tánger resultaba ingobernable. Gran Bretaña consideraba que ello era fundamentalmente debido a los problemas derivados de la no adhesión de Italia y de otros países (Portugal y los Estados Unidos) ${ }^{2}$. De hecho, a comienzos de 1926, once artículos del Estatuto tangerino no habían podido entrar todavia en vigor. Desde finales del año anterior, Gran Bretaña

1 Para las vicisitudes de la cuestión tangerina en 1923 y las negociaciones para la elaboración del Estatuto, véase: S. SUEIRO SEOANE, "España y el contencioso de Tánger: El Estatuto de 1923", en Actas del Congreso internacional "El Estrecho de Gibraltar», Ceuta, noviembre de 1987.

${ }_{2}$ Portugal se adhiere al Estatuto a finales de enero de 1926, pero no así Italia y EEUU. 
estaba realizando esfuerzos para lograr la viabilidad del régimen de Tánger tratando de conseguir la adhesión de Italia en unos términos que resultasen aceptables para Francia, la principal responsable de la exclusión italiana en 1923.

España va a aprovechar este replanteamiento de la cuestión para tratar una vez más de hacer valer sus intereses. Desde principios de 1926, Tánger vuelve a ser tema de editoriales y comentarios en los periódicos españoles. Toda la prensa coincide en afirmar la ineficacia del Estatuto. En la Revista Hispano Africana se leen, por ejemplo, frases como: «En la práctica, el fracaso ha sido de tal monta que ha superado los más negros augurios", o «la vida de la ciudad de Tánger se ha visto asfixiada entre las mallas del fracasado Estatuto internacional» ${ }^{3}$. Se esgrimen todos los argumentos posibles para demostrar lo ruinoso e inválido que ha acabado por ser el régimen existente.

Se alega, para empezar, que las disposiciones del Estatuto no son generales, como debe ser toda ley, ya que no se aplican a todas las naciones con presencia en la ciudad, constiuyendo coacción para aquellas que lo han suscrito e impunidad para aquellas que se han mantenido al margen: «Mientras que españoles, franceses e ingleses estén obligados al acatamiento de las disposiciones emanadas del nuevo régimen - hasta hoy perjudiciales y sin la menor ventaja - y los norteamericanos, italianos y portugueses continúen en libertad de proceder como hasta aquí, sin reconocer otra autoridad que la de sus cónsules respectivos, mal podrá desenvolverse la población ni avanzar en su vida ${ }^{4}$.

Otra de las críticas que se hacen al Estatuto es que ha sumido a Tánger en una total degradación política, social y económica. Son frecuentes los artículos que se refieren a la decadencia de la agricultura, el comercio y la industria, y a las huelgas y manifestaciones en que se materializa el descontento. En un editorial de El Telegrama del Rif se afirma: «En la administración no hay dinero para pagar a los empleados y las obras públicas han sido suspendidas. Muchas empresas han cerrado, otras han sido embargadas por deudas. Parte de los obreros han

${ }^{3}$ Véase durante los años 1926 y 1927 la Revista Hispano Africana y España en África, así como V. RuIz AlBÉNIz, Tánger y la colaboración franco-española en Marruecos, Madrid 1927.

${ }^{4}$ Crónica del corresponsal de El Sol en Tánger, LóPEZ RIENDA, tachada en su momento por la censura y aparecida en 1930 en el folletín que publica El Sol, con el título de España bajo la Dictadura. Siete años sin ley, pág. 238. 
emigrado con la protección de sus respectivos consulados. Los que restan advierten que no pueden seguir viviendo en esta miseria criminal de ahora, y no claman contra los patronos, sino contra el régimen ${ }^{5}$.

Pero para los españoles, lo peor del Estatuto es que no ha logrado en absoluto que Tánger deje de ser un foco de intrigas. Es éste el argumento recurrente y el más sólido con que cree contar el Gobierno en favor de su reivindicación: al amparo de la neutralidad tangerina, se sigue fomentando la rebeldía rifeña y actúan impunemente todo tipo de contrabandistas y "logreros", a pesar de que en virtud del artículo 10 del Estatuto quedaba prohibido realizar en Tánger trabajos de propaganda, agitación o preparación de empresa alguna que tendiera a alterar el orden de las zonas francesa y española de Marruecos. Esta era la prueba irrefutable de que el Estatuto no se cumplía. Mientras la neutralidad continuase siendo violada de esa forma, toda la labor de España en Marruecos sería inútil: "La zona internacional de Tánger, ahora y siempre, esterilizará todo el admirable esfuerzo de nuestros soldados (...). Malgastará España su tiempo, su dinero y la sangre generosa de sus hijos mientras siga siendo Tánger el centro de acción de todos los intrigantes, aventureros y contrabandistas, aprovechados pescadores de aguas turbias, que encuentran aquí ambiente propicio para todas sus maniobras ${ }^{6}$.

\section{TODA ESPAÑA, CONTRA «LA FALACIA DE LA INTERNACIONALIZACIÓN"}

La prensa española no se refería sólo a la ineficacia del Estatuto de 1923 sino a la del régimen internacional en general. Muchos seguían considerándolo, además, como una afrenta para España. Un furibundo africanista llegaba a afirmar: "Considerado bajo todos los puntos de vista, la internacionalización de Tánger es una aberración, un atentado contra las leyes de la Geografía, una coacción moral y material contra España fraguada por las más bastardas ambiciones; una cuña clavada en el co-

${ }^{5}$ El Telegrama del Rif, Melilla, 24 de agosto de 1926, editorial: «España en Tánger. La verdad de lo que está aconteciendo", por S. FERNÁnDEZ.

${ }^{6}$ Folletín de El Sol, crónica de LOPEZ RIENDA, pág. 240. 
razón de nuestra zona, capaz de impedir que reine en la misma la paz y la tranquilidad" ? .

El régimen internacional no sólo era el causante de la desorganización y la anarquía que reinaba en la ciudad, sino que era un engaño y estaba completamente desnaturalizado desde el momento en que Francia ejercía una influencia preponderante: "No es internacional un régimen en el que se manifiesta de un modo irrefutable el predominio de una de las naciones adheridas (...). La orientación y el resultado de todas las cuestiones serán siempre los que Francia haya determinado de antemano. Si esto no es un nacionalismo disimulado con un ligero barniz internacional, dígasenos lo que significa» ${ }^{8}$.

Con todos estos argumentos, los periódicos españoles alentaban desde sus páginas a contribuir al hundimiento del régimen tangerino: «Hay un objetivo claro y determinado para los intereses de España: derribar el Estatuto. Lo demás vendrá por sí solo» ${ }^{9}$.

El Gobierno de Primo de Rivera no había llegado, desde luego, a reconciliarse con el convenio de 1923, que sólo había aceptado por la fuerza de las circunstancias. Por su parte, las autoridades españolas de Tánger no facilitaban la labor y no dejaban de aprovechar cualquier ocasión para evidenciar lo impracticable del régimen tangerino. El secretario del FO, Austen Chamberlain, mostraba su disgusto y preocupación por la actitud de España que, según sus propias palabras, «desde el día en que estampó su firma en ese instrumento (el convenio de 1923) no ha mostrado nunca un deseo real de que obtuviera éxito" ${ }^{10}$. Chamberlain, además, acusaba al Gobierno español de obstruccionismo económico en Tánger con fines políticos ya que, al establecer un cordón aduanero alrededor de la ciudad internacional, privaba a Tánger de su importante comercio con la Zona española de Marruecos, con la reconocida intención de arruinar la economía tangerina. El secretario del FO había abrigado esperanzas de que, a pesar de la insatisfacción y la desgana con que España se había adherido al convenio de París de 1923, con el paso

7 España en África, 15 de octubre de 1926, «Las próximas conferencias», por A. ALEGRET.

${ }^{8}$ Folletín de El Sol, pág. 239.

9 El Telegrama del Rif, 22 de abril de 1926, edit.: «España en Tánger. La intriga organizada y protegida", por S. FERNÁNDEZ.

${ }_{10}$ Austen Chaberlain a Horace Rumbold, 14 de abril de 1926. Public Record Office, FO $371 / 11910$. 
del tiempo olvidaría su decepción y aceptaría sensatamente la internacionalización como única solución capaz de conciliar los intereses de las distintas potencias implicadas. Sin embargo, lejos de ello, «van acumulándose rápidamente las pruebas de que espera ver fracasado el convenio como un primer paso para la incorporación de Tánger en su Zona" ${ }^{11}$.

Efectivamente, ya en marzo de 1926, tanto el rey Alfonso XIII como Primo de Rivera habían aludido, en conversaciones con el embajador inglés, a la necesidad de que Tánger formase parte de la Zona española $y$, concretamente, el 17 de ese mes, Alfonso XIII había sugerido la posibilidad de llegar a un arreglo según el cual, el Gobierno español aceptaría posponer la consideración de su demanda de un puesto permanente en el Consejo de la Sociedad de Naciones a cambio de una modificación del régimen de Tánger a favor de España ${ }^{12}$. El rey, que no dejó de reconocer ante el embajador que se trataba de una proposición un tanto innoble por lo que tenía de chantaje, se refirió a la posible concesión a España de un mandato de cinco años sobre Tánger, de forma que la ciudad pudiera seguir manteniendo en alguna medida la administración internacional. No obstante, en la campaña de prensa, de inspiración oficial, que se iniciaba en España unas semanas después, se reclamaba la incorporación pura y simple de Tánger en la Zona española.

Estaba claro que, tras el éxito obtenido con el desembarco de Alhucemas, Primo de Rivera creía llegado el momento de que España desempeñara un papel de más peso en la escena internacional. Una y mil veces se repetía el argumento de que Tánger constituía una mutilación del Protectorado español y que su existencia suponía un enorme gasto en hombres y dinero, empleados en tratar de evitar que desde la zona internacional se enviasen armas y víveres a Abd-el-Krim. Alfonso XIII había dicho que España tenía 146 puestos distribuidos alrededor de Tánger con este objeto. Pero ni a Francia ni a Inglaterra impresionaba ya este argumento, al que contraponían el de que no existía constancia de que el contrabando desde Tánger a la Zona española supusiera una apreciable ayuda para los rebeldes. Chamberlain calificaba esa ayuda de «insignificante". Ambos países argumentaban además que los españoles tendrían que

\footnotetext{
1 Ibidem.

12 En febrero de ese año, España había planteado su reivindicación en Ginebra, amenazando con retirarse de la organización internacional si ésta no era satisfecha.
} 
realizar un esfuerzo igual, si no mayor, para atender a la defensa de Tánger en el caso de que se pusiera fin al régimen internacional.

El Gobierno inglés había recibido especialmente mal la demanda española por el momento elegido para plantearla ya que, como hemos dicho, por entonces se estaban llevando a cabo negociaciones con Italia para lograr que el Gobierno de Mussolini accediera a reconocer el convenio vigente, y corregir así uno de sus principales defectos. Al ser conocida, la componeda propuesta por España - Tánger a cambio del puesto permanente en la Sociedad de Naciones- fue objeto de duros comentarios por parte de la prensa europea, que calificó la actitud del Gobierno español de «inadmisible», «incalificable» e «irresponsable», considerando "gravísimo el hecho de que España se esfuerce en ejercer un chantaje sobre las demás potencias interesadas, subordinando el "mercado" de Ginebra al "mercado" de Tánger. Al emplear tales procedimientos, la diplomacia española se ha situado en medio del arroyo" ${ }^{13}$. "La autoridad internacional de España ha descendido a cero", afirmaba otro periódico ${ }^{14}$.

Chamberlain, asombrado e irritado, decide dar a conocer con firmeza al Gobierno español cuál es la actitud de Gran Bretaña y en tal sentido envía instrucciones a su embajador en Madrid, Horace Rumbold: "Ya es hora de que ese Gobierno baje de las nubes y se ponga en contacto con la realidad. No pueden derivarse más que perjuicios de que continúe abrigando cualquier ilusión errónea sobre la posición del Gobierno británico» ${ }^{15}$. Y a continuación añadía que Primo de Rivera debía convencerse de una vez por todas de que Gran Bretaña nunca consentiría que Tánger perteneciera a una sola de las potencias interesadas en el Mediterráneo y el norte de África. Era necesario hacerle abrir los ojos ante la imposibilidad de realización de las pretensiones españolas. No obstante, durante la visita de Alfonso XIII a Inglaterra en el mes de junio y ante la amenaza de abandonar la Sociedad de Naciones, se le hizo saber que, al objeto de que España permaneciera en Ginebra, donde tan eficaz era la labor del representante español, Quiñones de León, el Gobierno inglés no se opondría a la petición española de un mandato sobre Tánger, siempre que los términos del mandato impidieran por completo la fortifi-

\footnotetext{
${ }_{13}$ Daily News, 29 de agosto de 1926.

14 Journal des Débats, 13 de septiembre de 1926.

${ }^{15}$ PRO, FO 371/12718, Spain, Annual Report, 1926. Véase también: PRO, FO 371/ 11912, Chamberlain a Crewe (París), 16 de julio de 1926.
} 
cación de la ciudad o su conversión en base naval o militar. En cualquier caso, Gran Bretaña no actuaría como valedora de España en esta cuestión. Desde luego, para Chamberlain resultaba evidente que ni Francia ni Italia se avendrían a un mandato español y así era en efecto aunque, si bien Francia lo declaraba abiertamente, la actitud de Italia era solapada puesto que, como enseguida veremos, al tiempo que aseguraba a España que apoyaría su demanda, afirmaba en Gran Bretaña y Francia que sólo aceptaría una solución internacional que garantizase los derechos italianos.

\section{EL JUEGO DE MUSSOLINI}

Las negociaciones que Francia e Italia llevaban a cabo a instancias de Gran Bretaña, para conseguir la adhesión italiana al Estatuto parecen hallarse paralizadas en abril de 1926, a causa de la actitud dilatoria del Gobierno de Mussolini. Está aquí ya el germen de lo que será a partir de ahora su política en relación con la cuestión de Tánger. Influido por las ideas de su agente diplomático en esa ciudad, Vanutelli Rey, al que Carocci describe como «diplomático brillante y un poco fantasioso» ${ }^{16}$, el Duce creía que, si retrasaba deliberadamente la ratificación del Estatuto, podría obtener del Gobierno francés concesiones en otras esferas de mayor interés para Italia (una de sus mayores aspiraciones era que Francia reconociera la nacionalidad italiana a los residentes en el Protectorado francés de origen italiano ${ }^{17}$ ). Para el Gobierno de Mussolini, la cuestión de Tánger era sobre todo una cuestión de honor y de amor propio, tras la humillación sufrida por la exclusión de que había sido objeto en la Conferencia de 1923. Es en el Marruecos francés donde realmente tenía intereses importantes, y de ahí que su estrategia consista siempre en

${ }^{16}$ G. CAROccl: La politica estera dell'talia fascista, 1925-1928. Bari 1969.

${ }^{17}$ A Mussolini le preocupa hondiamente la desnacionalización emprendida por Francia con los italianos de Túnez y de Marruecos. De los 100.000 italianos que viven en la colonia francesa de Túnez, alrededor de la mitad han nacido allí pero conservan la nacionalidad italiana en virtud de un convenio de 1896. Francia quiere poner fin a esta situación anómala con una política de desnacionalización que, desde luego, pretende imponer también en su protectorado marroquí, donde Italia no está amparada por ningún convenio semejante al de Túnez, y donde viven unos 10.000 italianos. 
utilizar el tema tangerino con vistas a obtener ventajas en el marco general de Marruecos. Por esta razón, en mayo, ante el éxito de la campaña militar hispano-francesa contra Abd-el-Krim, Mussolini da a conocer su decisión de posponer su respuesta sobre su adhesión al Estatuto tangerino ya que, según él, estos acontecimientos creaban una nueva situación en Marruecos que debía discutirse en una conferencia general en la que, además de Francia y España, estuvieran también presentes Inglaterra e Italia. Sin embargo, tanto el Gobierno francés como el español afirmaron taxativamente que los asuntos marroquies derivados de la rendición de Abd-el-Krim eran una cuestión que les atañía exclusivamente a ellos y no permitirían la intervención italiana. Es por ello por lo que Mussolini se decide finalmente a presentar un memorándum con las demandas italianas en Tánger, relativas en general a una mayor representación de Italia en las diversas esferas de la administración de la zona internacional. Sin embargo, el Duce verá de nuevo el cielo abierto cuando España, en agosto, presenta oficialmente su demanda de incorporación o mandato sobre Tánger. Mussolini, de nuevo influido por las sugerencias de Vanutelli Rey, decide alentar a España a mantenerse firme en esta máxima reivindicación, prometiéndole el apoyo italiano. Cree que si España se mantiene inflexible en esta reclamación, ante el «impasse» resultante de la imposibilidad de que sea aceptada, las potencias acabarían por reconocer la necesidad de convocar una conferencia internacional sobre Marruecos en la que Italia podría obtener ventajas mucho más importantes que una mayor representación en la administración tangerina.

\section{LA RECLAMACIÓN OFICIAL ESPAÑOLA}

El Gobierno francés, aconsejado por el británico, se había mostrado dispuesto a hacer concesiones a Italia si ésta prestaba su inmediata adhesión al convenio de Tánger. Se pretendía así zanjar la cuestión y evitar que los españoles continuaran su campaña pro Tánger español. Estaba a punto de reunirse una comisión para estudiar el memorádum presentado por Mussolini cuando España presentó oficialmente su reclamación.

El 15 de agosto de 1926, en la nota en la que de forma oficial se solicitaba Tánger, Primo de Rivera decía: «España tiene la convicción de que fue una injusticia y un error sacar a Tánger y su pequeña zona del regateado y mínimo protectorado que se le asignó en Marruecos. Ello parece acusar desconfianza en nuestra aptitud para administrarlo, o en 
nuestra lealtad para mantenerlo neutral (...). Después de nuestra gestión de 17 años en Marruecos y de haber pasado por la prueba de la difícil neutralidad en la Gran Guerra, y de haber sacrificado en Marruecos acaso 40.000 vidas y mas de 5.000 millones de pesetas., creo que no es mucho pedir a las naciones que acuerden la inclusión de Tánger en el Protectorado español y le confíen su administración y mantenimiento de la neutralidad (...). No hay precedente de que ningún protectorado esté mediatizado, intervenido como esta éste del Marruecos español, precisamente en su célula más vital e importante».

La nota de la reclamación española es enviada no sólo a Francia y Gran Bretaña, sino también a Italia, que no figuraba como sabemos entre las potencias signatarias del convenio de 1923. Ello unido a que acaba de firmarse -el 7 de agosto- un tratado de amistad hispano-italiano hace que surjan toda clase de especulaciones sobre la posible existencia de cláusulas secretas relativas a Tánger ${ }^{18}$. Pero, a pesar de las noticias publicadas en la prensa extranjera, no es cierto que Primo de Rivera y Mussolini se hayan puesto de acuerdo en la cuestión tangerina. El presidente español envía la nota a Roma, no en virtud de un acuerdo previo con los italianos, sino porque espera contar con la ayuda de Mussolini y, por su parte, este último, como hemos dicho, cree poder sacar partido de la demanda española y decide hacer creer a España que cuenta con su apoyo. El tratado hispano-italiano carecía en realidad de importancia política.

\section{LA CONFERENCIA FRANCO-ESPAÑOLA DE 1927}

La propuesta de Primo de Rivera, muy del agrado de Mussolini, de convocar una conferencia internacional con la presencia de Gran Bretaña, Francia, Italia y Estados Unidos, para estudiar la demanda española, no es aceptada por los Gobiernos francés e inglés. Francia propone una conferencia tripartita anglo-franco-española, pero Italia se opone tajantemente a ser nuevamente excluida, amenazando con negarse a prestar su apoyo a ningún acuerdo sobre Tánger, e Inglaterra finalmente sugiere

${ }^{18}$ Se rumoreaba que, a cambio del apoyo italiano a la reclamación española, el Gobierno español había accedido a que Italia utilizara las islas Baleares como base naval en caso de conflicto bélico. 
la conveniencia de que tengan lugar unas conversaciones preliminares entre Francia y España y que, una vez conseguido un principio de acuerdo, Gran Bretaña e Italia sean invitadas a unirse a la negociación. De esta forma, Italia, al verse tratada en iguales condiciones que Inglaterra, no podría oponer ninguna objeción.

Las conversaciones franco-españolas se inician en París a principios de 1927. La perspectiva de un acuerdo entre Francia y España se presenta muy difícil toda vez que Francia se opone a una modificación sustancial del régimen de Tánger mientras que el Gobierno español, a juzgar por la campaña de prensa que está instigando para preparar el ambiente, parece seguir aspirando a la incorporación de Tánger a su zona de Protectorado, o al menos a un control efectivo de la ciudad. El Gobierno francés conoció por la prensa las demandas que le iban a ser formuladas y la prensa francesa protestó por lo que consideraba unos métodos de diplomacia muy poco correctos, señalando que España olvidaba que no era ella la única potencia interesada en Tánger y que, desde luego, la forma en que los españoles administraban su zona de Protectorado no estaba exenta de crítica. Todo esto contribuyó a que las conversaciones se iniciasen en un clima de controversia.

Para Francia era condición imprescindible que cualquier alteración que se estipulase encajase dentro del marco de los tratados que regulaban la zona internacional de Tánger, y atribuía asimismo una gran importancia al mantenimiento de la soberanía del Sultán. Los franceses alegaban que no podían abandonar al Sultán ya que, al erigirse en su sostén, habían creado una especie de nacionalismo marroquí que no toleraría que los derechos del Sultán sobre Tánger se viesen disminuidos. En España, por el contrario, la Liga Africanista, presidida por Antonio Goicoechea, dirigía a Primo de Rivera una carta - publicada en $A B C$ el 6 de febrero- en la que se hacían constar las demandas mínimas que, según la Liga, el Gobierno español debía exigir al francés en las negociaciones de París. Entre estas demandas figuraban la designación del Mendub por el Jalifa de Tetuán sobre una lista de nombres propuesta por España, la sustitución del tribunal mixto por un tribunal español, la reducción de la zona internacional a los límites de la ciudad, siendo el resto del territorio incorporado a la zona española, la desaparición del cargo de administrador y del Comité de Control, la modificación de la Asamblea, el control de la policía por un jefe y oficiales españoles, etc. Como contrapartida, España se comprometía a observar la neutralidad de la zona, garantizar la libertad religiosa y respetar la igualdad económica de las naciones extranjeras, así como el derecho de éstas a mantener escuelas $\mathrm{y}$ otros establecimientos pertenecientes a sus connacionales. 
Primo de Rivera contestó a esta carta diciendo que, en lo fundamental, la Liga coincidía con sus propios puntos de vista y que en ellos se habian basado las instrucciones enviadas a los negociadores españoles. En sus conversaciones con los Embajadores francés e inglés, el presidente del Consejo reivindicaba la anexión pura y simple de Tánger al Protectorado español de Marruecos, con el compromiso de garantizar la no fortificación de la ciudad y respetar su carácter especial cuanto fuera posible. Primo de Rivera se manifestaba contrario al régimen internacional, que creía que nunca funcionaría adecuadamente, y abogaba por que la ciudad y su «hinterland» estuviesen controladas por una potencia débil como España, puesto que si estaban en manos de una nación poderosa como Francia, Gran Bretaña o Italia, el resultado sería la ruptura del equilibrio de poder en el Mediterráneo.

El 19 de febrero de 1927, el cónsul general de Francia en Tánger recibía el texto de las demandas españolas que reclamaba la absoluta incorporación de Tánger en la zona española y apuntaba vagamente la posibilidad de una entrega de todo el Protectorado a los italianos si dichas demandas no eran atendidas. Esta amenaza velada parecía confirmar los rumores sobre un acuerdo secreto entre España e Italia relativo a Tánger. A pesar de que las cancillerías de París y Londres no suponian a Primo de Rivera muy dispuesto a embarcarse en aventuras poco claras como la que entrañaba una alianza político-militar con Italia, eran al mismo tiempo conscientes de que la frustración española en la cuestión de Tánger jugaba a favor de las intenciones de "captación» de España abrigadas por Mussolini. Primo de Rivera iba a utilizar, desde luego, la amenaza de su amistad con Italia para presionar a favor de sus demandas. Su estrategia consistirá en una combinación de amenazas y transacciones. Entre las primeras se encuentran la alianza con Italia y el abandono de todo el Protectorado. Entre las segundas iban a figurar desde la promesa de un trato favorable a Francia en las negociaciones comerciales con este país, hasta cesiones territoriales en otros lugares de Marruecos a favor de Francia.

De todas formas, en febrero del 27, Primo de Rivera había tenido tiempo de darse cuenta de que, debido sin duda a su inexperiencia en la gestión de la política exterior, habia tratado el asunto de un modo torpe y precipitado, lo que le había conducido a un callejón sin salida. Por medio de la Prensa, había movilizado a la opinión a favor del puesto permanente en el Consejo de la Sociedad de Naciones y de la inclusión de Tánger en el Protectorado español, relacionando estrechamente ambas demandas y suscitando de ese modo la irritación de británicos y 
franceses para los que se trataba de dos cuestiones totalmente distintas. Cuando quedó claro que no podría conseguir el puesto en Ginebra, Primo había tratado de utilizar todos los recursos a su alcance para obtener una compensación en Tánger que le permitiera salvar la cara y dar una satisfacción a la opinión pública, que era unánime en la reivindicación del enclave norteafricano. Lo cierto es que no había la más mínima posibilidad de que ni Francia ni Gran Bretaña aceptasen la tesis de un Tánger español, cualesquiera que fuesen las amenazas del Gobierno de Madrid, que no hacían sino causar pésima impresión en las cancillerías de ambos países. El secretario del FO señalaba al embajador español en Londres que no podía sino lamentar la forma en que su Gobierno había abordado la cuestión, y que no contribuía a facilitar la resolución del problema ni la demanda de anexión de Tánger sin más, ni la amenaza, aunque hubiera sido expresada delicadamente, de un abandono total de Marruecos en caso de no ser satisfecha su reivindicación ${ }^{19}$.

La amenaza de abandono de Marruecos venía de lejos y había sido esgrimida en otras ocasiones. Ahora eran nuevamente muchos los que se sumaban a la consigna de "o Tánger o nada». El argumento era que España evacuaría toda su zona si no conseguía Tánger porque su misión en Marruecos era una carga demasiado pesada de soportar si no podía controlar el foco de intrigas tangerino. España consideraba que ésta era una amenaza efectiva. frente a los franceses, a los que entonces se suponía reacios a llevar a cabo la ocupación de la zona española, y frente a los ingleses, puesto que se presumía que les inquietaría la posibilidad de que la costa opuesta a Gibraltar quedase en manos de una gran potencia como Francia. En sus declaraciones del 15 de agosto de 1926, Primo de Rivera había reiterado esta amenaza al afirmar que si no se lograba Tánger, "será cosa de pensar si, salvado brillantemente el honor de las armas en Marruecos, merece la pena dedicarle un par de cientos de millones al año para mantener en Tánger internacional el posible nido de nuevas conspiraciones y fácil modo de volver a armar al campo moro». Los Gobiernos francés e iriglés no daban excesiva importancia a estas insinuaciones, que interpretaban acertadamente como un «bluff", ya que estaba claro que para Primo de Rivera sería muy difícil afrontar la gran pérdida de prestigio que supondría el abandono de Marruecos, viéndose expuesto a la acusación de que todos los sacrificios de sangre y dinero habian sido en vano. No obstante, el abandono de la Sociedad de Naciones a principios de septiembre de 1926 era una palpable mues-

19 PRO, FO 371/13439, Spain, Annual Report, 1927. 
tra de que no podía descartarse por completo una acción imprudente y poco meditada por parte del dictador, "dado su carácter impulsivo y tenaz". Al menos en esa ocasión, "había cometido la locura de cumplir su amenaza» ${ }^{20}$. De cualquier forma, Chamberlain transmitía a Primo a través de su embajador que el Gobierno británico no se sentiría turbado por falta de sucesor si España decidía retirarse. Otra potencia mediterránea ocuparía su puesto.

A finales de marzo de 1927, la prensa española publicaba que el Gobjerno de Madrid, «sin modificar su original punto de vista», había preguntado al de París qué solución preveía para evitar las dificultades que la aplicación del vigente estatuto planteaba para el ejercicio del Protectorado español. Por la documentación diplomática, sabemos que Primo de Rivera, adoptando una actitud más conciliadora, proponía un reajuste favorable a Francia de la frontera entre las zonas española y francesa de Marruecos en el Valle del Uarga, a cambio de que Francia diera satisfacción a España en Tánger. Francia, en contrapartida por la obtención de esta ventaja, sólo se manifestó dispuesta a acceder a la inclusión en la zona española de una pequeña porción de Tánger -un área de unos $70 \mathrm{~km}^{2}$ al sudeste- Chamberlain no pudo por menos que llamar la atención a ambos Gobiernos subrayando la gravedad que Gran Bretaña atribuía a cualquier alteración de las fronteras de Tánger y la importancia de mantener el principio de inviolabilidad de la zona. La actitud de Gran Bretaña, a lo largo del contencioso tangerino, consistirá en defeñder sus intereses (mantenimiento del status quo mediterráneo y de una solución internacional para Tánger) y desempeñar al mismo tiempo un papel de árbitro en la disputa franco-española.

A finales de mayo, todavía no se había conseguido llegar a ningún resultado en unas negociaciones que duraban ya cuatro meses. El Gobierno español había ido modificando gradualmente sus originales demandas, abandonando primero su petición de incorporación de Tánger, desechando después su aspiración de desempeñar una posición preponderante en la zona internacional, y acabando finalmente por limitar su reivindicación a un único punto: la obtención de un control efectivo de la policía tangerina. Francia, sin embargo, se niega tajantemente a acceder a esta solicitud, que España considera el mínimo aceptable. Primo de Rivera, irritado con los franceses (y probablemente también consigo mismo por haber inflamado a la opinión española con la quimérica ilusión

20 Ibidem. 
de un Tánger español), vuelve a la carga con sus amenazas sobre un posible entendimiento con Italia, asegurando que si se llegaba a una ruptura de las conversaciones podría decidirse a orientar la política española por una "vía nueva", ya que "los constantes gestos amistosos de Mussolini estaban empezando a ser apreciados por los españoles» ${ }^{21}$. Pero, al mismo tiempo, el dictador español ofrece importantes compensaciones a Francia si tan sólo ésta consiente en alguna concesión real en Tánger. Está dispuesto a ofrecer en Marruecos a los franceses toda la zona de Beni Zerual, asi como otras rectificaciones de frontera entre ambos Protectorados, y se muestra también favorable a dar un trato de favor a Francia durante las negociaciones comerciales que van a desarrollarse próximamente. Primo de Rivera quería despejar este «punto negro» que empañaba la política de colaboración hispano-francesa en Marruecos que tan satisfactorios resultados estaba dando ${ }^{22}$, pero no podía asumir la humillación que supondría el no conseguir nada para España en la reforma del Estatuto tangerino.

A principios de agosto se decidía suspender las conversaciones que no se reanudarian hasta el mes de octubre, una vez transcurrido el verano. Durante este paréntesis, Gran Bretaña seguirá ejerciendo su función mediadora. Chamberlain tratará, por un lado, de suavizar la excesiva intransigencia francesa, presionando a Briand para que, con espíritu conciliador, tome directamente en sus manos las riendas de la negociación, y por otro lado, aconsejará moderación a Primo de Rivera ante algunos nuevos síntomas de recuperación de la "amistad italiana». El secretario del FO hace observar al jefe del Gobierno español que si su país desea conservar relaciones cordiales con Gran Bretaña, ello entraña necesariamente buenas relaciones también con Francia. En la entrevista con el dictador en Palma de Mallorca en el mes de septiembre, Chamberlain volvió a referirse a la cordialidad de las relaciones franco-británicas con la intención de disuadirle de embarcarse en una política anti-francesa de la mano de Italia.

\section{Ibidem.}

${ }_{22} \mathrm{Al}$ atacar Abd-el-Krim la zona francesa en la primavera de 1925, el Gobierno francés se había decidido por fin a proponer al español una colaboración militar en Marruecos para derrotar a los rebeldes rifeños. En el marco de esta colaboración se llevará a cabo el desembarco español en Alhucemas y la posterior rendición de Abd-el-Krim. 


\section{LOS ÚLTIMOS «COLETAZOS» DEL PRETENDIDO ENTENDIMIENTO HISPANO-ITALIANO}

Ya sabemos que Mussolini no quiere conformarse con la admisión de Italia en las conversaciones tangerinas, sino que se ha propuesto obtener beneficios más sustanciosos en el norte de África. Por eso, durante 1927 ha seguido animando a Primo de Rivera a mantenerse firme en sus demandas, a "no ceder ante eventuales contrapropuestas francesas», con la idea de forzar la convocatoria de una conferencia cuatripartita en la que Italia pueda conseguir ventajas en el Marruecos francés. Ha hecho creer al dictador que apoyará su demanda de un Tánger español, pero cuando el marqués de Estella, ante la inamovible oposición de Francia y la actitud de Inglaterra -en absoluto dispuesta a actuar de valedor de España frente a Francia- renuncia a esta aspiración y opta por la vía de la transigencia, Mussolini decide descubrir todo su juego ante su colega español: "Es conveniente -escribe a su embajador en Madridque el Gobierno español sepa que lo que preocupa hondamente al Gobierno italiano es la desnacionalización emprendida por Francia con los 10.000 italianos residentes en el Protectorado francés (...). España tiene, como nosotros, una decena de miles de súbditos cuya desnacionalización prepara Francia (...). Un frente único italo-español de firme resistencia acabaría por inducir a Inglaterra y a Francia a pensar en algún arreglo y alguna compensación en el sentido deseado por España e Italia (...). Primo de Rivera debe persuadirse de que es de gran interés para su país alargar las discusiones sobre Tánger, en vez de contentarse con algún éxito aislado y local, que nos constreñiría también a nosotros» ${ }^{23}$. Efectivamente, si Francia y España llegaban a un acuerdo y éste se sometía luego a Inglaterra e Italia como cosa hecha, se desmoronarian por completo los planes de Mussolini.

Primo de Rivera no está dispuesto a entrar en el juego italiano pero, del mismo modo que Mussolini pretende utilizarle para conseguir sus objetivos, él utilizará a su vez al Duce para conseguir los suyos propios: presionar a Francia con el fantasma de su entendimiento con Italia para que modifique su actitud intransigente en la cuestión de Tánger. En este contexto, en el otoño de 1927, en vísperas de la reanudación de las

${ }^{23}$ Documenti Diplomatici Italiani, vol. IV, 320, Mussolini a Medici. Roma, 11 de julio de 1927. Véase también: DDI, vol. V, 504, De Peppo, encargado de negocios, a Mussolini, Madrid, 5 de noviembre de 1927. 
conversaciones hispano-francesas de París, vuelven a producirse una serie de indicios de una amistad hispano-italiana al parecer renovada. En el mes de octubre, Mussolini, en un gesto de demostración de fuerza, manda desembarcar una división naval italiana en Tánger con el pretexto de celebrar el quinto aniversario de la Marcha sobre Roma. A pesar de la irritación que este golpe de efecto del jefe fascista provoca en toda Europa, el general Goded asiste a las fiestas italianas que tienen lugar en la ciudad internacional. A los pocos días, el rey Alfonso XIII viaja a Nápoles y aunque el motivo oficial de su visita es su asistencia a una boda, surgen innumerables especulaciones sobre la relación que su viaje pueda tener con un supuesto acuerdo hispano-italiano sobre Tánger. Además, coincidiendo con estos acontecimientos, se crea en la Embajada italiana de Madrid un puesto de agregado naval que no existía desde la guerra, y se designa para cubrirlo a un oficial de marina de alta graduación. Estos síntomas de acercamiento entre las dos penínsulas mediterráneas generan un ambiente de nerviosismo en la prensa francesa e inglesa. No obstante, en las cancillerías de París y Londres existe el convencimiento de que el dictador español no llegará a embarcarse en ningún acuerdo con Mussolini contra su vecino del norte y que su amistad con Italia no será más que platónica. El embajador inglés expresa perfectamente cuál es su actitud: «El General Primo de Rivera en realidad no ha confiado nunca plenamente en los italianos. Ha flirteado con ellos, y sus flirteos han coincidido generalmente con los períodos en los que se sentía insatisfecho por la actitud del Gobierno francés hacia sus demandas en Tánger. En otras palabras, ha utilizado su aparente aproximación a Italia como un fantasma con el que alarmar a los franceses» ${ }^{24}$.

\section{PUNTO FINAL}

Primo de Rivera opta por la única actitud realista posible, la del acuerdo con Francia, conformándose con la modesta concesión del mando del tabor de policía a la que finalmente ha accedido Francia, aconsejada por Gran Bretaña. En este sentido, Alfonso XIII es muy explícito cuando, ante la insistencia del embajador italiano para que España no transija, afirma que la única política exterior posible para su país por el momento es la de estar bien avenido con Francia e Inglaterra y que «las

\footnotetext{
${ }^{24}$ PRO, FO 371/13439, Spain, Annual Report, 1927.
} 
circunstancias imponen a España una postura de prudencia y contemporización". El rey, a juzgar por sus conversaciones con este embajador ${ }^{25}$, sueña con una alianza hispano-italiana, aunque reconoce que «hoy España no está todavía en condiciones de desafiar abiertamente al frente unido anglo-francés». «Dentro de cuatro años - dice- cuando haya progresado su organización militar, naval y aeronaútica, España podrá hacer oír su propia voz más eficazmente» ${ }^{26}$. Primo de Rivera no comparte la italofilia del monarca y desconfía de las intenciones de Mussolini, que ha estado ocultando sus verdaderas cartas mucho tiempo. En cualquier caso, pasados los momentos de euforia en que había creido que España podía aspirar a desempeñar un papel de mayor peso en el escenario internacional, comprendía ahora lo utópico de su pretensión.

Durante el año 1928 se reunirán las cuatro potencias interesadas para acabar de concretar las reformas del Estatuto de 1923. El 25 de julio se firmará el nuevo convenio, que se ratificará el 6 de septiembre. También en 1928, España regresará al seno de la Sociedad de Naciones, sin puesto permanente, de la misma forma que sin Tánger.

\section{CONCLUSIONES}

Además del interés que la cuestión de Tánger tiene en sí misma, a través de su estudio pueden analizarse las claves de la política mediterránea de la época. Las relaciones entre Gran Bretaña, Francia, España e Italia en este período, y las pautas que siguen sus respectivas políticas exteriores, quedan perfectamente reflejadas en el contencioso tangerino. Desde el punto de vista de España, que es el que principalmente nos interesa analizar, Tánger constituye un microcosmos donde se ponen claramente de manifiesto las características fundamentales de la política exterior de la Dictadura. Primo de Rivera, llevado por su anhelo de que España desempeñe un papel más activo e influyente en los asuntos internacionales, actúa impulsivamente al plantear su reivindicación en términos imposibles de aceptar por las demás potencias, pero al mismo

${ }_{25}$ MAE-Roma, Politica, b. 1591, tel. núm. 47/27, Medici a Musolini, Madrid, 10 de enero de 1928. Véase también: $D D I$, vol. VI, 118, Medici a Mussolini, 25 de marzo de 1928, y tel. núm. 1878/942, Medici a Mussolini, 18 de diciembre de 1928.

${ }^{26} \mathrm{DDI}$, Vol. V, 623, Medici a Mussolini. Madrid, 27 de noviembre de 1927. 
tiempo se muestra realista, al entender que la amistad con Francia y Gran Bretaña es la única vía posible y deseable para España. Francia, el molesto vecino del norte, es el principal enemigo de las pretensiones españolas, pero es asimismo el país al que más ligados están sus intereses, lo que llevará finalmente a la Dictadura a claudicar en Tánger, no dejándose arrastrar a la aventura de una inteligencia con Italia propuesta por Mussolini. La amistad con esta "hermana latina", más aparente que real, será sólo el arma esgrimida por España para ejercer presión y tratar de ser tenida más en cuenta por sus dos tradicionales aliadas. En la solución alcanzada, Gran Bretaña juega un importante papel por su actitud conciliadora, siempre pendiente de la no alteración del statu quo en el Mediterráneo, y en ningún caso dispuesta a apoyar iniciativas contrarias a su alianza con Francia. 